\title{
ẢNH HƯỞNG CỦA SỬ THAY ĐỔI CÁC YẾU TỐ KHÍ TƯợNG NHẠY CẢM ĐẾN NĂNG SUẤT LÚA Ở TỈNH VĨNH LONG
}

\author{
Đặng Thị Thanh Lêe ${ }^{1}$ Nguyễn Kỳ Phùng²
}

Tóm tắt: Biến đổi khi hậu (BĐKH) sẽ tác động rất lớn đến lĩnh vực nông nghiệp cu thể là ảnh hương đến năng suất cây trồng. Do vậy, nghiên cứu đã sử dưng mô hình hỗ trợ chuyển giao kỹ thuật nông nghiệp (DSSAT) nhằm dụ báo ảnh hưởng của sụ thay đổi các yếu tố khi tuợng do BĐKH đến năng suất lúa. Nghiên cứu được thực hiện tại 8 đơn vị ở tỉnh Vĩnh Long bao gồm 6 huyện Bình Tân, Long Hồ, Măng Thít, Tam Bình, Trà Ôn, Vũng Liêm; thị xã Bình Minh và Thành phố Vĩnh Long. Kết quả nghiên cưu cho thấy mô hình DSSAT mô phỏng khá tốt năng suất lúa ờ vùng nghiên cứu cu thể hệ số tuoong quan tính toán được trong giai đoạn hiệu chỉnh là $R^{2}=0,998$. Với kịch bản phát thải RCP4.5 và RCP8.5 năng suất lúa trên toàn tỉnh ò̀ các mốc thời gian 2030; 2050 và 2100 có xu hưóng giảm.

Từ khóa: Mô hình DSSAT, năng suất lúa, Vĩnh Long.

Ban Biên tập nhận bài: 08/12/2018 Ngày phản biện xong: 15/02/2019 Ngày đăng bài: 25/02/2019

\section{Giới thiệu}

Sản xuất nông nghiệp là hoạt động đặc biệt quan trọng và có ý nghĩa sống còn đối với các nước châu Á, lúa gạo là một trong những loại cây lương thực quan trọng nhất ở khu vực này [13]. Diện tích lúa chiếm 24 triệu ha đất canh tác nông nghiệp ở châu Á [3] và cũng là nguồn lương thực quan trọng ở các nước Đông Á, Đông Nam Á và Nam Á. Nông nghiệp là một trong những ngành sản xuất quan trọng Việt Nam với khoảng $60-70 \%$ dân số tham gia, diện tích đất nông nghiệp chiếm gần $75 \%$ diện tích tự nhiên, Việt Nam đứng thứ 3 thế giới về sản xuất lúa gạo sau Ấn Độ và Thái Lan [4], những năm qua, nông nghiệp đạt tốc độ tăng trưởng bình quân 4.3\%, đóng góp 15-16\% tổng thu nhập quốc nội GDP. Tuy nhiên, Việt Nam cũng như các nước khác trong khu vực và trên thế giới đang đứng trước một thách thức và chịu tác động nặng nề của $\mathrm{BĐKH}$ và nước biển dâng [7]. Được cho là ${ }^{1}$ Đại học Khoa học Tụ Nhiên-Đại Học Quốc Gia Thành phố Hồ Chí Minh

${ }^{2}$ Viện Khoa Hoc \& Công Nghệ Tính Toán Thành phố Hồ Chí Minh

Email: ledang1711@gmail.com ngành chịu tổn thương cao nhất, nền nông nghiệp luôn phải chịu những thiệt hại hết sức nặng nề, ước tính mỗi năm nước ta tổn thất khoảng 14500 tỷ đồng tương đương với 1.2\% GDP cả nước, trong đó riêng lĩnh vực nông nghiệp chiếm gần 800 tỷ đồng. Theo tính toán sản lượng lúa xuân có nguy cơ giảm 1,2 triệu tấn; lúa mùa giảm 743,8 ngàn tấn vào năm 2030 . Việt Nam sẽ là nước mất an ninh lương thực nếu không có giải pháp thích ứng kịp thời.

Vĩnh Long là tỉnh thuộc hạ lưu sông Mê Kông, nằm giữa sông Tiền, sông Hậu và ở trung tâm khu vực ĐBSCL, nông nghiệp là một thế mạnh của tỉnh, đặc biệt nghề trồng lúa đóng vai trò quan trọng trong vấn đề đảm bảo an ninh lương thực và đóng góp một phần không nhỏ trong cơ cấu kinh tế của tỉnh, tuy nhiên trong những năm gần đây, hoạt động trồng lúa của tỉnh phải gánh chịu nhiều thiệt hại do thiên tai gây ra.

Các mô hình mô phỏng cây trồng và các hệ thống hỗ trợ quyết định trong lĩnh vực nông nghiệp đã được sử dụng thành công ở nhiều nước trên thế giới [14]. Các mô hình mô phỏng cây trồng rất hữu ích cho đánh giá mối quan hệ giữa 
khí quyển và đất của cây trồng đối với các loại cây trồng đơn lẻ và luân canh phân tích theo mùa. Một trong những mục tiêu chính của mô hình mô phỏng cây trồng là để ước tính năng suất cây trồng [5]. Hệ thống hỗ trợ quyết định chuyển giao công nghệ nông nghiệp DSSAT (Decision Support System for Agro-technology Tranfer) là hệ thống hỗ trợ quyết định chuyển giao kỹ thuật nông nghiệp được phát triển đầu tiên bởi tập hợp các nhà khoa học trong "Hệ thống mạng lưới quốc tế” phục vụ chuyển giao kỹ thuật nông nghiệp. DSSAT cho phép người sử dụng thực hiện mô phỏng trong các điều kiện môi trường và quản lý cây trồng trong nhiều năm, để đánh giá các rủi ro trong điều kiện này[14]. CSMCERES-Rice là mô hình mô phỏng sự tăng trưởng và phát triển của cây lúa từ lúc xuống giống đến lúc thu hoạch - dựa trên các quá trình sinh trưởng của lúa đến đất và điều kiện thời tiết. Dữ liệu đầu vào cần thiết để chạy các mô hình DSSAT bao gồm dữ liệu thời tiết hàng ngày, bao gồm nhiệt độ tối đa và tối thiểu, lượng mưa và bức xạ mặt trời; dữ liệu đặc tính đất; giống cây trồng và thông tin quản lý cây trồng, như ngày cấy, thời gian cấy, khoảng cách hàng và cây, tỷ lệ, và ngày và lượng phân bón và ứng dụng tưới.
Nhiều nhà khoa học đã đánh giá mô hình lúa thành công và dự đoán hiện tượng, tăng trưởng, phát triển và năng suất lúa $[2,6]$, các nghiên cứu đều chỉ ra rằng biến đổi khí hậu sẽ tác động đáng kế đến tăng trưởng và phát triển của cây lúa trong tương lai, tại Việt Nam các nghiên cứu về ảnh hưởng của các điều kiện tương lai đến năng suất lúa cũng được các nhóm nghiên cứu ở Thái Bình [1] Long An [10], Cần Thơ [9], kết quả của các nghiên cứu đều cho thấy rằng, với các điều kiện khí hậu tương lai năng suất lúa ở từng vùng sẽ bị ảnh hưởng đáng kể.

Mục tiêu của nghiên cứu là xem xét đánh giá ảnh hưởng của của sự thay đổi các yếu tố khí tượng nhạy cảm đến năng suất lúa tại 8 huyện thuộc tỉnh Vĩnh Long.

\section{Phương pháp nghiên cứu}

\subsection{Vùng nghiên cứu}

Nghiên cứu được thực hiện tại 8 đơn vị hành chính của tỉnh Vĩnh Long gồm 6 huyện Bình Tân, Long Hồ, Măng Thít, Tam Bình, Trà Ôn, Vũng Liêm; thị xã Bình Minh và Thành phố Vĩnh Long. Vĩnh Long là tỉnh thuộc hạ lưu sông Mê Kông, nằm giữa sông Tiền, sông Hậu và ở trung tâm khu vực ĐBSCL, vị trí của vùng nghiên cứu được thể hiện trong hình 1 .

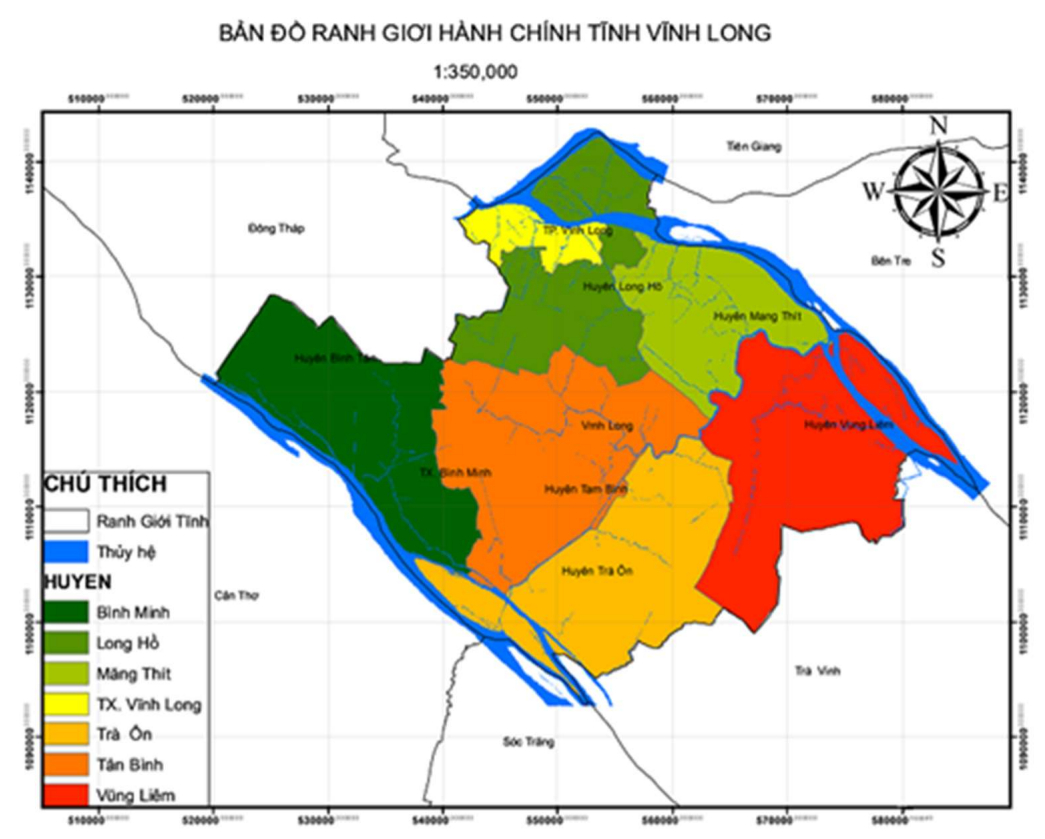

Hình 1. Phạm vi nghiên cứu 
Nằm trong vùng khí hậu nhiệt đới gió mùa, nhiệt độ trung bình hàng năm ở Vĩnh Long dao động trong khoảng $27,7^{\circ} \mathrm{C}-28^{\circ} \mathrm{C}$; tháng có nhiệt độ cao nhất là tháng $4,5\left(34,5-37,6^{\circ} \mathrm{C}\right)$, tháng 12 và tháng 1 có nhiệt độ thấp nhất $(19,2$ $24,3^{\circ} \mathrm{C}$ ), biên độ nhiệt dao động trong tháng khoảng $8,7-14^{\circ} \mathrm{C}$ vào mùa khô và từ $10-14,1^{\circ} \mathrm{C}$ vào mùa mưa. Tổng số giờ nắng trung bình trong năm khoảng 2700 - 2800 giờ; tổng lượng mưa trung binh hàng năm 1186 - 1193 mm; độ ẩm tương đối trung bình cả năm $80-81 \%$. Khu vực nghiên cứu có 3 nhóm đất chính là đất phèn, đất phù sa và đất lấp liếp. Theo đó đất phèn đất phèn tiềm tàng tầng sâu phân bố chính ở huyện Bình Minh, Tam Bình, Măng Thít, Long Hồ, Bình Tân và $T p$. Vĩnh Long, đất phù sa có tầng loang lổ đỏ vàng phân bố ở huyện Trà Ôn, và đất phènsâu hoạt động ở huyện Long Hồ. Thời vụ canh tác chính của tính bao gồm vụ chính Đông Xuân, Hè Thu và một vụ mùa Thu Đông.

\subsection{Mô hình DSSAT}

DSSAT là một tập hợp các chương trình độc lập hoạt động cùng với các mô hình mô phỏng nhiều loại cây trồng. Các cơ sở dữ liệu mô tả thời tiết, đất, các điều kiện thí nghiệm, các thông tin cho việc ứng dụng mô hình trong các tình huống khác nhau. Phần mềm này giúp người sử dụng xây dựng cơ sở dữ liệu và so sánh các kết quả được mô phỏng với kết quả quan sát được, giúp họ quyết định điều chỉnh để đạt được độ chính xác. Hệ thống DSSAT gồm có 3 phần chính: Hệ thống quản lý cơ sở dữ liệu dùng để nhập, lưu trữ và phục hồi các dữ liệu cần thiết; Tập hợp các chương trình dùng để mô phỏng quá trình tương tác giữa kiểu gen với môi trường và chương trình ứng dụng để phân tích và hiển thị các kết quả thực nghiệm.

Các thông số đầu vào mô hình

Các thông số đầu vào của mô hình DSSAT bao gồm các yếu tố về: đất đai- thổ nhưỡng, giống, phương thức canh tác, khí hậu thời tiết (Hình 2).

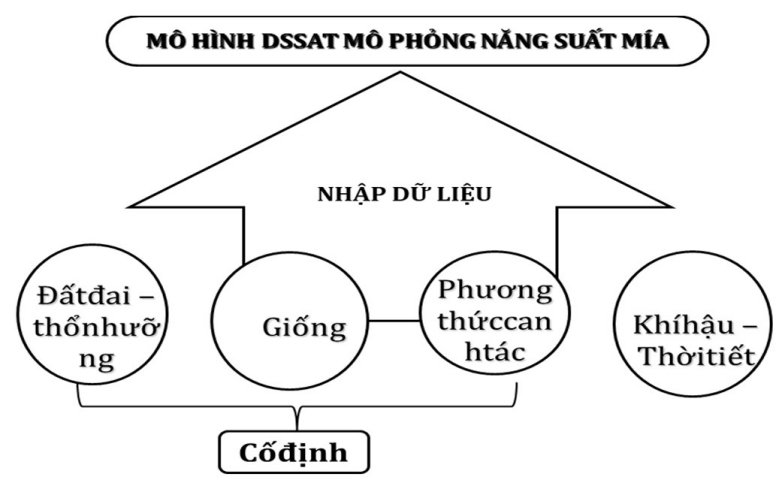

Hình 2. Các thông số đầu vào của mô hình

\section{DSSAT}

Giống lúa: VNĐ 95 -20; OM 1490; OM 576; OMCS 2000; IR 64; OM 2717; OM 2718; Jasmine 85; OM 3536 (OMCS 21) và $\mathrm{OM} 2517$.

Đặc tính đất:

+ Đất phèn tiềm tàng tầng sâu: huyện Bình Minh, Tam Bình, Măng Thít, Long Hồ, Bình Tân và TP. Vĩnh Long.

+ Đất phù sa có tầng loang lổ đỏ vàng: huyện Trà Ôn.

+ Đất phèn: huyện Long Hồ.

Phương thức canh tác: Đặc tính đất trồng lúa và kỹ thuật canh tác được thu thập, trích dẫn từ cuốn "Cẩm nang cây lúa" [11] ngoài ra tác giả còn tham khảo thêm thông số kỹ thuật, thành phần và hàm lượng các loại phân bón của cácnhà sản xuất phân bón ở thị trường Việt Nam.

Thời vu gieo trồng:

\begin{tabular}{cccc}
\hline Đợt gieo sạ & Đông Xuân & Hè Thu & Thu Đông \\
\hline Đợt 1 & $22 / 9-27 / 10$ & $01-29 / 02$ & $20-25 / 06$ \\
Đợt 2 & $5-12 / 11$ & $15 / 3-16 / 4$ & $05-07 / 07$ \\
Đợt 3 & $24 / 11-8 / 12$ & $25 / 4-15 / 5$ & $28 / 07-02 / 09$ \\
\hline
\end{tabular}

Khí hậu - Thời tiết: Dữ liệu về thời tiết vùng Vĩnh Long sử dụng trong mô phỏng được từ trường số liệu tái phân tích (CFSR viết tắt tì̀
"Climate Forecast System Reanalysis") của Mỹ [15] quy mô toàn cầu với bước lưới $0,5 \times 0,5^{\circ}$, bước thời gian là 6 giờ. Số liêuu thời tiết theo 


\section{BÀI BÁO KHOA HỌC}

ngày với đầy đủ 5 yếu tố: lượng mưa, nhiệt độ không khí lớn nhất, nhỏ nhất, độ ẩm không khí, bức xạ mặt trời, tốc độ gió với định dạng Excel sẽ được sử dụng. Dũ liệu được thu thập từ ngày 01/01/2008 đến ngày 31/12/2013.

\section{3. Đánh giá mô hình}

Sự phù hợp của mô hình được đánh giá thông qua hệ số tương quan $\mathrm{R}^{2}$ nhằm kiểm tra mối quan hệ tuyến tính giữa năng suất mô phỏng và năng suất thực tế. $\mathrm{R}^{2}>0,85$ : Tương quan tốt; $0,4<\mathrm{R}^{2}$ $<0,8$ : Tương quan khá; $\mathrm{R}^{2}<0,4$ : Tương quan thấp. Năng suất mô phỏng được kí hiệu là $X$, năng suất thực tế là $Y$. Công thức tính hệ số tương quan $\mathrm{R}^{2}$ :

$$
\mathrm{R}^{2}=\frac{\left[\sum_{\mathrm{i}=1}^{\mathrm{n}}\left(\mathrm{X}_{\mathrm{i}}-\mathrm{X}_{\mathrm{tb}}\right)\left(\mathrm{Y}_{\mathrm{i}}-\mathrm{Y}_{\mathrm{tb}}\right)\right]^{2}}{\sum_{\mathrm{i}=1}^{\mathrm{n}}\left(\mathrm{X}_{\mathrm{i}}-\mathrm{X}_{\mathrm{tb}}\right)^{2} \sum_{\mathrm{i}}^{\mathrm{n}}\left(\mathrm{Y}_{\mathrm{i}}-\mathrm{Y}_{\mathrm{tb}}\right)^{2}}
$$

\section{Kết luận và bàn luận \\ 3.1. Kết quả hiệu chỉnh và đánh giá mô hình mô hình}

Để hiệu chỉnh và đánh giá mô hình DSSAT, nghiên cứu đã tiến hành mô phỏng năng suất lúa vụ Đông Xuân, Hè Thu và Thu Đông tại 08 huyện ở tỉnh Vĩnh Long, giai đoạn từ 2009 2013. Với 120 nghiệm thức, được thiết lập bởi chuỗi dữ liệu khí tượng từ 2009 - 2013 và các thông số thu thập về biện pháp kỹ thuật canh tác. Năng suất lúa thực tế và năng suất lúa mô phỏng được thể hiện trong bảng 1 .

Bảng 1. Kết quả tính toán năng suất thực tế và mô phỏng 2009 - 2013

\begin{tabular}{|c|c|c|c|c|c|c|c|c|c|c|c|c|c|c|c|c|c|}
\hline \multirow{2}{*}{ Vụ } & \multirow{2}{*}{ Năm } & \multicolumn{2}{|c|}{ TP. Vĩnh Long } & \multicolumn{2}{|c|}{ Trà Ôn } & \multicolumn{2}{|c|}{ Bình Tân } & \multicolumn{2}{|c|}{ Tam Bình } & \multicolumn{2}{|c|}{ Vũng Liêm } & \multicolumn{2}{|c|}{ Măng Thít } & \multicolumn{2}{|c|}{ Long Hồ } & \multicolumn{2}{|c|}{ TX. Bình Minh } \\
\hline & & TT & MP & TT & $\mathrm{MP}$ & TT & MP & TT & MP & TT & MP & TT & MP & TT & MP & TT & MP \\
\hline \multirow{5}{*}{$\begin{array}{l}\text { Đông } \\
\text { Xuân }\end{array}$} & 2009 & 5800 & 5796 & 6845 & 6891 & 7183 & 7196 & 6664 & 6698 & 6772 & 6770 & 6769 & 6770 & 7044 & 7042 & 6685 & 6664 \\
\hline & 2010 & 6000 & 5702 & 7187 & 7148 & 6800 & 6848 & 6988 & 7006 & 7391 & 7402 & 6939 & 6929 & 7361 & 7402 & 7170 & 7148 \\
\hline & 2011 & 6000 & 6004 & 7167 & 7209 & 7012 & 6968 & 6704 & 6714 & 6086 & 6077 & 6347 & 6347 & 6728 & 6760 & 6086 & 6094 \\
\hline & 2012 & 6071 & 6111 & 6912 & 6961 & 6983 & 6973 & 6656 & 6621 & 6900 & 6923 & 6354 & 6306 & 6658 & 6653 & 6662 & 6703 \\
\hline & 2013 & 6300 & 6331 & 6377 & 6377 & 6601 & 6558 & 7101 & 7041 & 7011 & 7024 & 6608 & 6646 & 6876 & 6873 & 6896 & 6873 \\
\hline \multirow{5}{*}{ Iè Thu } & 2009 & 4220 & 4268 & 5037 & 5003 & 5286 & 5303 & 4904 & 4897 & 4983 & 5017 & 4981 & 4984 & 5184 & 5109 & 4919 & 4915 \\
\hline & 2010 & 4200 & 4203 & 5031 & 5035 & 4600 & 4645 & 4892 & 4931 & 5173 & 5187 & 4857 & 4874 & 5153 & 4130 & 5019 & 4983 \\
\hline & 2011 & 4460 & 4337 & 6113 & 6129 & 5753 & 5753 & 5718 & 5693 & 5191 & 5139 & 5414 & 5422 & 5738 & 5743 & 5191 & 5180 \\
\hline & 2012 & 4542 & 4615 & 6555 & 6538 & 5684 & 5631 & 6312 & 6289 & 6544 & 6580 & 6026 & 6002 & 6314 & 6290 & 6318 & 6300 \\
\hline & 2013 & 4700 & 4780 & 6498 & 6549 & 5728 & 5783 & 6312 & 6357 & 6232 & 6211 & 5874 & 5892 & 6112 & 6100 & 6130 & 6170 \\
\hline \multirow{5}{*}{$\begin{array}{l}\text { Thu } \\
\text { Đông }\end{array}$} & 2009 & 3430 & 3431 & 3658 & 3659 & 3839 & 3814 & 3562 & 3574 & 3620 & 3652 & 3618 & 3645 & 3765 & 3744 & 3573 & 3567 \\
\hline & 2010 & 3400 & 3434 & 4073 & 4077 & 4100 & 4081 & 3960 & 3958 & 4188 & 4147 & 3932 & 3964 & 4172 & 4178 & 4063 & 4074 \\
\hline & 2011 & 3550 & 3557 & 4809 & 4840 & 4640 & 4686 & 4498 & 4481 & 4083 & 4084 & 4259 & 4298 & 4514 & 4553 & 4083 & 4071 \\
\hline & 2012 & 3500 & 3500 & 4377 & 4329 & 5198 & 5218 & 4216 & 4257 & 4370 & 4372 & 4024 & 4234 & 4217 & 4260 & 4219 & 4241 \\
\hline & 2013 & 3900 & 3927 & 4525 & 4529 & 5470 & 5471 & 4396 & 4370 & 4340 & 4333 & 4091 & 4343 & 4256 & 4300 & 4269 & 4277 \\
\hline
\end{tabular}

(TT: Thực tế-MP: Mô Phỏng)

Mối liên hệ giữa năng suất tính toán và năng suất mô phỏng được đánh giá dựa vào hệ số tương quan $\mathrm{R}^{2}$. Mô hình DSSAT cho kết quả mô phỏng khá tốt so với thực tế, cụ thể hệ số tương quan tính toán được $\mathrm{R}^{2}$ là 0,992 . Bên cạnh đó năng suất lúa các vụ Đông Xuân, Hè Thu và Thu Đông ở năm 2009 cho kết quả khá sát với thực tế so với các năm còn lại, cụ thể năm 2009 hệ số $\mathrm{R}^{2}=0,99981$; năm 2010 hệ số $\mathrm{R}^{2}=0,98754$; năm 2011 hệ số $\mathrm{R}^{2}=0,99970$; năm 2012 hệ số
$\mathrm{R}^{2}=0,99892$; năm 2013 hệ số $\mathrm{R}^{2}=0,99863$. Như vậy dữ liệu của năm 2009 sẽ được chọn làm năm cơ sở, phục vụ tính toán năng suất lúa khu vực nghiên cứu theo kịch bản BĐKH.

\subsection{Kết quả mô phỏng năng suất lúa theo} kịch bản RCP 4.5 và RCP 8.5

Theo kịch bản RCP4.5: nhiệt độ trung bình năm trên toàn quốc vào đầu thế kỷ có mức tăng phổ biến từ $0,6-0,8^{\circ} \mathrm{C}$; vào giữa thế kỳ có mức tăng $1,3-1,7^{\circ} \mathrm{C}$; đến cuối thế kỳ có mức tăng 
$1,7-2,4^{\circ} \mathrm{C}$; lượng mưa năm vào đầu thế kỷ có xu thế tăng ở hầu hết cả nước, phổ biến từ $5-10 \%$, vào giữa cuối thế kỷ tăng $5-15 \%$.

Theo kịch bản RCP8.5: nhiệt độ trung bình năm trên toàn quốc vào đầu thế kỷ có mức tăng phổ biến từ $0,8-1,1^{\circ} \mathrm{C}$; vào giữa thế kỳ có mức tăng $2,0-2,3^{\circ} \mathrm{C}$ ở phía bắc và $1,8-1,9^{\circ} \mathrm{C}$ ở phía nam; đến cuối thế kỳ có mức tăng $3,3-4,0^{\circ} \mathrm{C}$ ở phía bắc và $3,0-3,5^{\circ} \mathrm{C}$ ở phía nam; lượng mưa năm vào đầu thế kỷ có xu thế tăng như kich bản RCP4.5.

Bảng 2. Bảng thông số mức tăng nhiệt độ trung bình và thay đổi lượng mura trung bình năm theo các kịch bản $B Đ K H$

\begin{tabular}{cccccccc}
\hline Kịch bản & & \multicolumn{3}{c}{ RCP4.5 } & \multicolumn{3}{c}{ RCP8.5 } \\
\hline Thông số & mùa & 2030 & 2050 & 2100 & 2030 & 2050 & 2100 \\
& xuân & 0.7 & 1.4 & 1.9 & 0.8 & 2 & 3.5 \\
Mức tăng nhiệt độ trung & hạ & 0.7 & 1.4 & 1.9 & 0.9 & 1.9 & 3.6 \\
bình $\left({ }^{\circ} \mathrm{C}\right)$ & thu & 0.6 & 1.3 & 1.8 & 0.7 & 1.9 & 3.4 \\
& đông & 0.8 & 1.5 & 1.9 & 0.9 & 2 & 3.5 \\
Mức thay đổi lượng mưa & xuân & 12.5 & 6.6 & 10.1 & 2.7 & 11.1 & 13.3 \\
$(\%)$ & hạ & 2.5 & 4.2 & 6.4 & 4.5 & 11.4 & 10.7 \\
& thu & 8 & 21.2 & 17.5 & 15.1 & 17.8 & 28.4 \\
& đông & 67.9 & 62 & 136 & 51.3 & 75.4 & 49.4 \\
\hline
\end{tabular}

Kết quả mô phỏng năng suất lúa ở các thời kì theo kịch bản RCP4.5 và RCP 8.5 được thể hiện ở bảng 3 .

Bảng 3. Kết quả tính toán năng suất lúa trong giai đoạn 2030-2100 theokịch bản BĐKH

\begin{tabular}{|c|c|c|c|c|c|c|c|c|c|c|c|c|c|c|c|c|c|}
\hline \multirow{3}{*}{ Vụ } & \multirow{3}{*}{ Năm } & \multicolumn{2}{|c|}{$\begin{array}{l}\text { TP. Vĩnh } \\
\text { Long }\end{array}$} & \multicolumn{2}{|c|}{ Trà Ôn } & \multicolumn{2}{|c|}{ Bình Tân } & \multicolumn{2}{|c|}{ Tam Bình } & \multicolumn{2}{|c|}{ Vũng Liêm } & \multicolumn{2}{|c|}{ Măng Thít } & \multicolumn{2}{|c|}{ Long Hồ } & \multicolumn{2}{|c|}{$\begin{array}{l}\text { TX. Bình } \\
\text { Minh }\end{array}$} \\
\hline & & $\mathrm{RCP}$ & RCP & $\mathrm{RCP}$ & $\mathrm{RCP}$ & RCP & $\mathrm{RCP}$ & $\mathrm{RCP}$ & RCP & RCP & RCP & RCP & RCP & RCP & $\mathrm{RCP}$ & $\mathrm{RCP}$ & $\mathrm{RCP}$ \\
\hline & & 4.5 & 8.5 & 4.5 & 8.5 & 4.5 & 8.5 & 4.5 & 8.5 & 4.5 & 8.5 & 4.5 & 8.5 & 4.5 & 8.5 & 4.5 & 8.5 \\
\hline \multirow{4}{*}{$\begin{array}{l}\text { Đông } \\
\text { Xuân }\end{array}$} & 2009 & \multicolumn{2}{|c|}{5796} & \multicolumn{2}{|c|}{6891} & \multicolumn{2}{|c|}{7196} & \multicolumn{2}{|c|}{6698} & \multicolumn{2}{|c|}{6770} & \multicolumn{2}{|c|}{6770} & \multicolumn{2}{|c|}{7042} & \multicolumn{2}{|c|}{6664} \\
\hline & 2030 & 5404 & 5416 & 6100 & 6111 & 5994 & 6020 & 5967 & 5978 & 5976 & 5987 & 5976 & 5987 & 6254 & 6265 & 5829 & 5844 \\
\hline & 2050 & 4451 & 3940 & 5068 & 4304 & 5060 & 4622 & 4941 & 4442 & 4941 & 4442 & 4941 & 4442 & 4907 & 4463 & 4910 & 4501 \\
\hline & 2100 & 4371 & 2842 & 4677 & 3414 & 4986 & 3739 & 4867 & 3288 & 4867 & 3288 & 4867 & 3287 & 4832 & 3579 & 4842 & 3641 \\
\hline \multirow{4}{*}{$\begin{array}{l}\text { Hè } \\
\text { Thu }\end{array}$} & 2009 & \multicolumn{2}{|c|}{4268} & \multicolumn{2}{|c|}{5003} & \multicolumn{2}{|c|}{5303} & \multicolumn{2}{|c|}{4897} & \multicolumn{2}{|c|}{5017} & \multicolumn{2}{|c|}{4984} & \multicolumn{2}{|c|}{5109} & \multicolumn{2}{|c|}{4915} \\
\hline & 2030 & 4236 & 4221 & 4550 & 4537 & 4844 & 4880 & 4540 & 4578 & 4627 & 4676 & 4637 & 4686 & 4793 & 4861 & 4592 & 4646 \\
\hline & 2050 & 4111 & 3793 & 4348 & 4091 & 4578 & 4134 & 4440 & 4100 & 4620 & 4349 & 4600 & 4216 & 4798 & 4391 & 4570 & 4180 \\
\hline & 2100 & 3930 & 3509 & 4089 & 3171 & 4281 & 3107 & 4151 & 3312 & 4415 & 3986 & 4364 & 3343 & 4567 & 4219 & 4379 & 3934 \\
\hline \multirow{4}{*}{$\begin{array}{l}\text { Thu } \\
\text { Đông }\end{array}$} & 2009 & \multicolumn{2}{|c|}{3431} & \multicolumn{2}{|c|}{3659} & \multicolumn{2}{|c|}{3814} & \multicolumn{2}{|c|}{3574} & & & & & & & & \\
\hline & 2030 & 3013 & 3081 & 3523 & 3515 & 3706 & 3696 & 3426 & 3498 & 3447 & 3480 & 3536 & 3540 & 3575 & 3569 & 3448 & 3438 \\
\hline & 2050 & 3058 & 2936 & 3411 & 3461 & 3666 & 3502 & 3462 & 3361 & 3417 & 3439 & 3299 & 3185 & 3554 & 3271 & 3410 & 3179 \\
\hline & 2100 & 3057 & 2828 & 3337 & 2936 & 3636 & 2768 & 3462 & 3219 & 3455 & 3202 & 3291 & 2963 & 3312 & 2253 & 3239 & 2235 \\
\hline
\end{tabular}

Năng suất vụ đông xuân theo các kịch bản năng suất thể hiện khác nhau cụ thể, năm 2030, BĐKH ở Vĩnh Long thể hiện rõ xu thế giảm ờ năng suất lúa giảm mạnh trên toàn tỉnh giảm các thời kì. Tuy nhiên ứng với từng giai đoạn mô khoảng $800 \mathrm{~kg} / \mathrm{ha}$ ở cả hai kịch bản so với năm phỏng, từng kịch bản lại có sự tăng giảm của 2009; năm 2050 năng suất lúa tiếp tục giảm, dao 
động trong khoảng $1800 \mathrm{~kg} / \mathrm{ha}$ với kịch bản $\mathrm{RCP} 4.5$ và $2300 \mathrm{~kg} / \mathrm{ha}$ với kịch bản RCP8.5, năm 2100 sản lượng lúa trên toàn tỉnh tiếp tục giảm, tương ứng là $1900 \mathrm{~kg} / \mathrm{ha}$ với kịch bản $\mathrm{RCP} 4.5$ và $3300 \mathrm{~kg} /$ ha với kịch bản RCP8.5.

Cũng giống như lúa vụ đông xuân, lúa vụ hè thu tại Vĩnh Long cũng chịu tác động của sự thay đổi quy luật phân bố của thời tiết khí hậu, năng suất hạt vụ hè thu cũng thể hiện rõ xu thế giảm trên 8 huyện trong phạm vi nghiên cứu. Năm 2030, năng suất không có sự biến động nhiều, sản lượng lúa ước tính giảm khoảng $300 \mathrm{~kg} / \mathrm{ha}$ với cả hai kịch bản. Năm 2050 năng suất có xu hướng giảm trên toàn tỉnh khoảng $500 \mathrm{~kg} / \mathrm{ha}$ với kịch bản RCP4.5 và $800 \mathrm{~kg} / \mathrm{ha}$ với kịch bản RCP8.5. Năm 2100 năng suất tiếp tục giảm, tuy nhiên giảm nhẹ hơn so với vụ đông xuân, 600 $\mathrm{kg} / \mathrm{ha}$ với kịch bản RCP4.5, $1300 \mathrm{~kg} / \mathrm{ha}$ với kịch bản RCP8.5.

Vụ lúa Thu Đông, năm 2030 năng suất lúa giảm khoảng $150 \mathrm{~kg}$ /ha với cả hai kịch bản; năm 2050 giảm $200 \mathrm{~kg} / \mathrm{ha}$ với kịch bản RCP4.5 và $350 \mathrm{~kg} /$ ha với kịch bản RCP8.5. Năm 2100, với kịch bản RCP4.5 năng suất lúa giảm khoảng 300 $\mathrm{kg} / \mathrm{ha}$, giảm $800 \mathrm{~kg} / \mathrm{ha}$ với kịch bản RCP8.5.

\section{Kết luận và kiến nghị}

Úng dụng mô hình DSSAT mô phỏng năng suất lúa cho kết quả tương đối tốt so với năng suất lúa thực tế.Kết quả nghiên cứu cho thấy phát triển lúa gạo ở Vĩnh Long đang đối mặt với những thách thức đáng kể do biến đổi khí hậu. Đối với điều kiện của vùng nghiên cứu, sự thay đổi các yếu tố khí tượng nhạy cảm như nhiệt độ, lượng mưa, bức xạ mặt trời trong tương lai năng suất lúa ở vùng nghiên cứu sẽ giảm.

\section{Tài liệu tham khảo}

1. Đoàn Văn Điếm, Trường Đức Trí, Ngô Tiền Giang (2010), Dự báo tác động của biến đổi khí hậu đến năng suất lúa ở huyện Thái Thụy, tỉnh Thái Bình. Tạp chí Khoa học và Phát triển: tập 8, số 6: $975-982$.

2. Yao, F., Xu, Y., in, E., Yokozawa, M., Zhang, J. et al. (2007), Assessing the impacts of climate change on rice yields in the main rice areas of China. Climatic Change 80, 395-409.

3. GOP (2007), Economic survey of Pakistan 2006-2007, finance division. Islamabad: Eco-nomic Advisory Wing, Finance Division, Govt. of Pakistan.

4. FAO (2014b), FAOSTAT. Online statistical database (available at http:// faostat.fao.org).

5. Hoogenboom, G., Jones, J.W., Wilkens, P.W., Porter, C.H., Batchelor, W.D., Hunt, L.A. et al. (2004a), Decision support system for agrotechnology transfer (DSSAT) version 4.0. Honolulu: University of Hawaii, CD-ROM.

6. Chowdhury, I.U.A. Khan, M.A.E. (2015), The impact of climate change on rice yield in Bangladesh: A time series analysis. BGC Trust University, Bangladesh. RJOAS, 4(40).

7. IPCC (International Plant Protection Convention) 2007, Summary for policymakers. In $S$. Solomon, D. Qin, M. Manning, Z. Chen, M. Marquis, K. Averyt, M. Tignor \& H.L. Miller, eds. Climate change 2007: the physical science basis. Contribution of working group I to the Fourth assessment report of the Intergovernmental Panel on Climate Change. Cam-bridge, UK, and New York, USA, Cambridge University Press

8. Jing, Q., Keulen, H.V., Hengsdijk, H., Cao, A., Bindraban, P.S., Dai, T. et al. (2009), Quantifying $N$ response and $N$ use efficiency in rice-wheat $(R W)$ cropping system under differ-ent water management. Journal of Agricultural Sciences, 147, 303-312.

9. Nguyễn Thị Hà Mi, Võ Quang Minh (2014), Khoa Môi trường \& Tài nguyên Thiên nhiên, Trường Đại học Cần Thơ. Đánh giá múc độ ảnh hưởng đến canh tác lúa tỉnh An Giang trên co sở các kịch bản biến đổi khí hậu khác nhau. Tạp chí Khoa học Trường đại học Cần Thơ, số 3, trang 42-52. 
10. Nguyen Ang Thuy An, Tran Duong Thien Loc, Nguyen Ky Phung (2015), Impact Assessment of Climate Change on Maize Yield of Long An Province (Vietnam) under B2 Scenario by DSSAT. Proceedings of the 3rdEnvironment Asia International Conference on "Towards International Collaboration for an Environmentally Sustainable World" Thai Society of Higher Education Institutes on Environment, Montien Riverside Hotel, Bangkok, Thailand, June 17-19, 2015 (English).

11. Nguyễn Văn Hoan. (2006), Cẩm nang cây lúa. Nhà xuất bản Lao động, 385 trang

12. Paul, M.B., Linfield, C.B. (2002), Statistics for environmental engineering, 2th Edition, Lewis publishers by CRC press LLc, pp. 512.

13. Singh, U., Patil, S.K., Das, R.O., Padilla, J. L., Singh, V. P., Pal, A.R. (1999), Nitrogen dynamics and crop growth on an alfisol and a vertisol under rainfed lowland rice-based crop-ping system. Field Crops Research, 61, 237-252.

14. Tsuji, G.Y., Hoogenboom, G., Thornton, P.K. (1998), Understanding options for agricultural production. Systems approaches for sustainable agricultural development. Dordrecht: Kluwer Academic.

15. https://cfs.ncep.noaa.gov/cfsr/.

\title{
INFLUENCE OF METEOROLOGICAL SENSITIVE PARAMETERS ON RICE YEILD IN VINH LONG PROVINCE
}

\author{
Dang Thi Thanh Le ${ }^{1}$, Nguyen Ky Phung² \\ ${ }^{1}$ Universiity of Science, VNU \\ ${ }^{2}$ Institute for computational science and technology
}

\begin{abstract}
Climate change will impact significantly on the agricultural sector, especially for crop yields. This research applied Decision Support System for Agro technology Transfer model (DSSAT) to estimate the impact of climate change on rice production according to climate change scenarios: RCP4.5 and RCP8.5. This study was implemented at Vinh Long Province including: Binh Tan, Long Ho, Mang Thit, Tam Binh, Tra On, Vung Liem District, Binh Minh Town and Vinh Long City of Vinh Long Prov-ince. The DSSAT model showed a close relationship with the measured values by correlation coefficient $\left(R^{2}=0.998\right)$. The results also showed a reduction of average rice yield in 2030, 2050 and 2100 in Vinh Long province.
\end{abstract}

Keywords: DSSAT model, rice production, Vinh Long Province. 